\title{
Two Different Cytochrome P450 Enzymes Are the Adrenal Antigens in Autoimmune Polyendocrine Syndrome Type I and Addison's Disease
}

\author{
Ola Winqvist, * Jan Gustafsson, ${ }^{*}$ Fredrik Rorsman, * F. Anders Karlsson, * and Olle Kämpe * \\ Departments of * Internal Medicine and ${ }^{\ddagger}$ Pediatrics, University Hospital, Uppsala, S-751 85 Sweden
}

\begin{abstract}
Autoimmune polyendocrine syndrome type I (APS I) and idiopathic Addison's disease are both disorders with adrenal insufficiency but with differences in genetic background, clinical presentation, and extent of extraadrenal manifestations. In this study the major adrenal autoantigen identified with sera from patients with APS I was characterized by analyses using indirect immunofluorescence, Western blots of adrenal subcellular fractions and of recombinant proteins, immunoprecipitations of $\left[{ }^{35} \mathrm{~S}\right]$ methionine-labeled lysates of a human steroid-producing cell line, and studies of enzymatic activity. Sera from patients with APS I, identifying cells in adrenal glands and testes involved in steroid synthesis, reacted in Western blots with a 53-kD antigen, which comigrated with the cytochrome P450 cholesterol side chain cleavage enzyme (SCC). The sera also immunoprecipitated this protein from lysates of radiolabeled adrenal cells. The enzymatic activity of SCC was inhibited by the APS I sera but not by control sera. Sera from patients with idiopathic Addison's disease did not react with the SCC. The results show that the autoimmune responses towards adrenal tissue in patients suffering from APS I and Addison's disease are remarkably selective and suggest that a determination of the antigen involved in a patient with autoimmune adrenal insufficiency will have diagnostic as well as prognostic implications. (J. Clin. Invest. 1993. 92:2377-2385.) Key words: sidechain cleavage enzyme $\bullet 21$-hydroxylase $\bullet$ autoantigen $\bullet$ autoantibodies $\bullet$ autoimmunity
\end{abstract}

\section{Introduction}

Autoimmune polyendocrine syndrome type I (APS I), ${ }^{1}$ Blizzard's syndrome, is a rare disorder with an autosomal recessive pattern of inheritance (1). Apart from adrenal insufficiency, the endocrine features of the syndrome include hypoparathyroidism, gonadal insufficiency, and less frequently insulin-dependent diabetes mellitus (2-4). Nonendocrine manifestations such as chronic mucocutaneous candidiasis (5), chronic active hepatitis, alopecia, and vitiligo also form part of the syn-

Address correspondence to Dr. Ola Winqvist, Department of Internal Medicine, University Hospital, S-751 85 Uppsala, Sweden.

Received for publication 23 March 1993 and in revised form 28 June 1993.

1. Abbreviations used in this paper: APS I, autoimmune polyendocrine syndrome type I; FSH, follicle-stimulating hormone; IPTG, isopropyl $\beta$-D-thiogalactoside; LH, luteinizing hormone; SSC, side chain cleavage enzyme.

J. Clin. Invest.

(c) The American Society for Clinical Investigation, Inc.

0021-9738/93/11/2377/09 \$2.00

Volume 92, November 1993, 2377-2385 drome (2). The patients with APS I often display immunological abnormalities such as hypergammaglobulinemia, selective IgA deficiency, and defective T cell function (6). In idiopathic Addison's disease, the autoimmune adrenalitis may occur isolated, although thyroiditis, diabetes mellitus, and vitiligo often are associated disorders. We have recently found that the major autoantigen in idiopathic Addison's disease is 21-hydroxylase (7), an enzyme involved in the biosynthesis of cortisol and only expressed in the adrenal cortex. The clinical course of the adrenal insufficiency in APS $I$ is different from that in Addison's disease, with an onset of symptoms during the first or second decade of life (4). Furthermore, the disorders differ with respect to genetic markers, in that APS I shows a weak linkage to HLA A28 (8), whereas idiopathic Addison's disease seems to be associated with HLA B8 (9) and HLA DR3 (10). The fact that the two forms of adrenalitis present such different features prompted us to examine the humoral immune responses to the adrenal gland.

\section{Methods}

Patients. Sera were obtained from five patients with APS I. Their ages range was 5-19 yr and the follow-up period spanned 4-11 yr. Mucocutaneous candidiasis was the first sign of disease in all the patients. Clinical signs of adrenal insufficiency developed at an average age of $5.2 \mathrm{yr}$ (range, 1.5-10), and all the patients were subsequently given hydrocortisone acetate replacement therapy. Patients 4 and 5 were also being treated with prednisolone and azathioprine therapy for chronic active hepatitis. Patients 1 and 2 were under treatment with 1,25-dihydroxycholecalciferol for hypoparathyroidism. Patient 1 also showed signs of gonadal insufficiency, with incomplete pubertal development and raised levels of follicle-stimulating hormone (FSH) and luteinizing hormone (LH). Two of the patients (nos. 1 and 5) were siblings. These two patients and patient 4 were all of Finnish origin. Patient 3 had had a younger sister who died when $5 \mathrm{yr}$ old with a clinical picture of increased intracranial pressure and liver failure after chronic active hepatitis (11). Patient 4 had had an older sister who died when $5 \mathrm{yr}$ old of hypocalcemic and/or Addison crises, likewise retrospectively assessed as a component of APS I. The patients also suffered from additional manifestations such as alopecia, vitiligo, and malabsorption (Table I) to varying degrees. Sera were also obtained from 15 patients (aged 19-77 yr) with idiopathic Addison's disease. All these sera identified 21-hydroxylase as the major adrenal autoantigen in Western blots using bovine adrenal homogenates (7). Sera from 15 healthy blood donors were used as controls. The serum cholesterol levels in the patients and controls all fell within the normal range and the means did not differ between the groups.

Antibodies. A polyclonal antiserum was raised against bacterially expressed human cytochrome P450 side chain cleavage enzyme (SCC) produced in Escherichia coli by the pET-SCC vector, a generous gift from Dr. B. C. Chung (Institute of Molecular Biology, Academia, Taipei, Taiwan). Rabbit sera raised against bovine $11 \beta$-hydroxylase, bovine cytochrome P450 SCC, and porcine 17 $\alpha$-hydroxylase were purchased from Oxygen (Dallas, TX). A rabbit serum raised against 21-hydroxylase was kindly provided by Dr. P. C. White (Cornell University Medical College, New York). FITC- and alkaline-conjugated antibodies directed against human or rabbit IgG were purchased from Dako- 
patts (Glostrup, Denmark) and Bio-Rad Laboratories (Richmond, CA) for immunofluorescence and Western blots, respectively.

Indirect immunofluorescence. Unfixed frozen sections of human adrenal glands and testes and of rat adrenal glands were incubated overnight at $4^{\circ} \mathrm{C}$ with patient sera diluted to end-point titers. After three washes in PBS the sections were exposed to the species-specific FITC-labeled IgG antibodies for $30 \mathrm{~min}$ (7).

Preparation of antigen. Bovine adrenal glands were obtained at a local abattoir and immediately placed on ice. Mitochondrial and microsomal subcellular fractions were prepared by mincing the glands in a blender and then treating them by differential centrifugation in the presence of PMSF (Sigma Chemical Co., St. Louis, MO) (7). Protein concentrations were measured with the BCA protein assay (Pierce Chemical Co., Rockford, IL).

The $E$. coli strain BL21(DE3) obtained, containing the pET-SCC vector, was multiplied and then induced with $0.4 \mathrm{mM}$-isopropyl $\beta$-Dthiogalactoside (IPTG; Sigma Chemical Co.). The fusion protein thus generated was dissolved in $6 \mathrm{M}$ guanidine hydrochloride $(\mathrm{GdnHCl}$; Sigma Chemical Co.) and then precipitated by adding a $50 \mathrm{mM}$ Tris$\mathrm{HCl}$ buffer, pH 8.0, containing $200 \mathrm{mM} \mathrm{NaCl}, 0.1 \mathrm{mM}$ EDTA, 0.1 $\mathrm{mM}$ dithiothreitol, and $0.5 \%$ glycerol dropwise to a final concentration of $1 \mathrm{M} \mathrm{GdnHCl}$. The precipitate was redissolved in $6 \mathrm{M} \mathrm{GdnHCl}$, and subjected to chromatography on a hydroxyapatite column (Bio-Rad Laboratories). The purified fusion protein, with a molecular mass of $55 \mathrm{kD}$, was collected in the flow-through fraction as described (12) and then used for immunization in rabbits (Dakopatts) and for the Western blots.

To induce expression of $17 \alpha$-hydroxylase, the human modified cDNA clone in the expression vector pCWmod17 (gift from Dr. M. Waterman, University of Texas, Dallas, TX), was electroporated into the E. coli strain JM 109 (Invitrogen, San Diego, CA). Protein expression was induced by $1 \mathrm{mM}$ IPTG for $48 \mathrm{~h}$ at $28^{\circ} \mathrm{C}$ and the protein was purified as described (13).

The full-length cDNA for human 21-hydroxylase was cut out from the p21-T7-f1 plasmid (kindly given by Dr. P. C. White) and ligated into the eukaryotic expression vector pSV7d at the BamHI site. The pSV7d-c21 was cotransfected with a neomycin-resistance vector into CHO cells using the lipofectin method as outlined by the manufacturer (Life Technologies, Gaithesburg, MD). Cells were selected by using the neomycin-derivative G-418 sulfate (Life Technologies). Clones were picked and checked for 21-hydroxylase expression using specific antisera and immunoprecipitations of $\left[{ }^{35} \mathrm{~S}\right]$ methionine labeled $\mathrm{CHO}$ transformants as described below.

Western blot analysis. Approximately $50 \mu \mathrm{g}$ of protein from a mitochondrial fraction or $10 \mu \mathrm{g}$ of bacterially expressed protein (SCC or $17 \alpha$-hydroxylase) was heated in a $0.1 \mathrm{M}$ Tris $/ \mathrm{HCl}, \mathrm{pH} 8.8$, sample buffer containing $10 \%$ sucrose, $3 \%$ SDS, $10 \mathrm{mM}$ dithiothreitol, and trace amounts of bromophenol blue, and then separated on a $10-15 \%$ gradient SDS-PAGE and transferred overnight to nitrocellulose paper using $200 \mathrm{~mA}$ of a constant current. Subsequently, nitrocellulose strips were blocked with gelatin (Bio-Rad Laboratories) and incubated for 2 $\mathrm{h}$ with patient sera that had been diluted to $1: 100$. Prestained standards (Bio-Rad Laboratories) were included in all the strips to secure correct alignment. Proteins were detected by incubation for $1.5 \mathrm{~h}$ with alkaline phosphatase-conjugated species-specific anti-IgG antibodies, followed by the $p$-nitro blue tetrazolium chloride/s-bromo-4-chloro-3-indoyl phosphate $p$-toluidine salt color development system as recommended (Bio-Rad Laboratories) (7).

Immunoprecipitation. A human adrenocortical cell line, $\mathrm{NCI}$ H295 (American Type Culture Collection, Rockville, MD), was grown in hydrocortisone insulin transferrin $17 \beta$-estradiol and sodium selenite medium (14). Cells were washed twice with the methioninefree RPMI 1640, incubated with $0.75 \mathrm{mCi}^{35} \mathrm{~S}$-methionine (Amersham International, Amersham, UK) for $12 \mathrm{~h}$, harvested with a rubber policeman, washed twice, and then lysed on ice for $1 \mathrm{~h}$ in a $20 \mathrm{mM}$ Tris$\mathrm{HCl}$ buffer, $\mathrm{pH} 8.0$, containing $150 \mathrm{mM} \mathrm{NaCl}, 0.01 \% \mathrm{NaN}_{3}, 1 \mathrm{mM}$ PMSF, $1 \%$ Triton X-100, and $1 \%$ aprotinin (Trasylol; Bayer, Leverkusen, Germany). The lysate was centrifuged at $100,000 \mathrm{~g}$ for $30 \mathrm{~min}$ to remove debris. The radioactivity of the supernatant was determined and $10 \times 10^{6} \mathrm{cpm}$ were used for each immunoprecipitation. The lysates were precleared overnight at $+4^{\circ} \mathrm{C}$ with serum from a healthy blood donor. They were then incubated for $20 \mathrm{~min}$ with five times the volume of a 20\% suspension of Staphyloccocus aureus Cowan strain 1 (a kind gift from Professor L. Rask, Swedish University of Agricultural Sciences, Uppsala, Sweden) and spun for $3 \mathrm{~min}$ to reduce unspecific background. Aliquots of the precleared lysates were then again incubated overnight at $+4^{\circ} \mathrm{C}$ in the prescence of either patient sera or polyclonal rabbit antisera. After adding $S$. aureus and collecting the precipitate the bacterial pellets were washed six times with a $0.2 \%$ Triton $\mathrm{X}-100$ containing Tris- $\mathrm{HCl}$ buffer with or without $0.5 \mathrm{M} \mathrm{NaCl}$, in three cycles. The final wash was carried out with redistilled water and the pellets were then heated in sample buffer (15). The supernatants were subjected to SDS-PAGE. Gels were fixed in methanol/acetic acid and incubated for $30 \mathrm{~min}$ in Amplify (Amersham International). Fluorography was carried out at $-70^{\circ} \mathrm{C}$ on dried gels.

Assay for enzymatic activity. Bovine adrenal gland homogenates were prepared in $0.25 \mathrm{M}$ sucrose with $10 \mathrm{mM}$ Tris- $\mathrm{HCl}$ buffer, $\mathrm{pH} 7.0$, and $1 \mathrm{mM}$ EDTA. The mitochondrial fraction was obtained by stepwise centrifugations, once at $800 \mathrm{~g}$ and twice at $8,500 \mathrm{~g}(16)$. The mitochondrial pellet was suspended in $10 \mathrm{mM}$ Tris- $\mathrm{HCl}, \mathrm{pH} 7.0 .2 \mathrm{mg}$

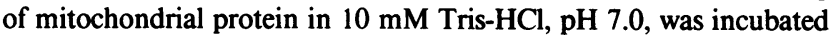
with $6 \mu \mathrm{g}$ of $\left[4-{ }^{14} \mathrm{C}\right] \mathrm{cholesterol}$ ( $\mathrm{sp}$ act, $61 \mathrm{Ci} / \mathrm{mol}$, Amersham International) in a total volume of $1 \mathrm{ml}$. Before use, the $\left[4-{ }^{14} \mathrm{C}\right]$ cholesterol was purified by chromatography on aluminium oxide, grade III (Woelm, Eschwege, Germany) (17). The incubation mixtures were supplemented with $10 \mu \mathrm{mol}$ of $\mathrm{CaCl}_{2}$ and $1 \mu \mathrm{mol}$ of $\beta$-nicotinamide adenine dinucleotide phosphate (Sigma Chemical Co.). In inhibition experiments 30- $\mu$ l aliquots of patient sera were added. Before the addition of $\left[4-{ }^{14} \mathrm{C}\right]$ cholesterol, a 5 -min preincubation at $37^{\circ} \mathrm{C}$ was carried out. The reactions were terminated by the addition of $10 \mathrm{vol}$ of chloroform/ methanol $(2: 1[\mathrm{vol} / \mathrm{vol}])$. The chloroform extracts were subjected to thin layer chromatography using cyclohexane-ethyl acetate (3:2 [ vol/

Table I. Characteristics of the Five APS I Patients

\begin{tabular}{|c|c|c|c|c|c|c|c|c|c|c|c|c|}
\hline \multirow[b]{3}{*}{ Patient } & \multirow[b]{3}{*}{ Sex } & \multirow[b]{3}{*}{ Age } & \multirow{3}{*}{$\begin{array}{c}\text { Duration of } \\
\text { disease }\end{array}$} & \multicolumn{4}{|c|}{ Endocrine } & \multirow{2}{*}{\multicolumn{5}{|c|}{ Nonendocrine }} \\
\hline & & & & \multirow{2}{*}{$\begin{array}{c}\text { Adrenal } \\
\text { insufficiency }\end{array}$} & \multirow[b]{2}{*}{ Hypoparathyroidism } & \multirow{2}{*}{$\begin{array}{c}\text { Gonadal } \\
\text { insufficiency }\end{array}$} & \multirow[b]{2}{*}{ Hypothyroidism } & & & & & \\
\hline & & & & & & & & Candidiasis & Hepatitis & Alopecia & Vitiligo & Malabsorption \\
\hline & & $y r$ & $y r$ & & & & & & & & & \\
\hline 1 & $\mathrm{~F}$ & 17 & 11 & $+(10)^{*}$ & + & + & - & + & - & + & + & - \\
\hline 2 & $\mathbf{M}$ & 14 & 11 & $+(8)$ & + & - & - & + & - & - & - & + \\
\hline 3 & $\mathbf{M}$ & 19 & 17 & $+(13)$ & - & - & + & + & - & + & + & - \\
\hline 4 & $\mathrm{~F}$ & 7 & 5 & $+(4)$ & - & - & - & + & + & + & - & + \\
\hline 5 & $\mathbf{M}$ & 6 & 5 & $+(3)$ & - & - & - & + & + & - & - & - \\
\hline
\end{tabular}

$+/-$ denotes presence or absence of the specified manifestation. * Duration of adrenal insufficiency is within parentheses. 
vol]) as the mobile phase (18). Unlabeled pregnenolone (Sigma Chemical Co.) was used as an external standard. The radioactivities in the zones corresponding to cholesterol and pregnenolone were assayed with a thin layer scanner (Berthold, Karlsruhe, Germany).

\section{Results}

Immunofluorescence. When human and rat adrenal glands were stained with sera from patients with APS I and from those with idiopathic Addison's disease, a pattern restricted to the cortex was observed with all sera. The strongest cytoplasmatic intensity was noted in the outermost layer, i.e., the zona glomerulosa (Fig. 1, $A$ and $B$ ), as reported previously (19-21). This staining was identical to the pattern obtained with a rabbit antiserum against SCC. When an antiserum against $17 \alpha-$ hydroxylase was used, the rat adrenal cortex did not stain and the zona glomerulosa in the human adrenal gland stained only faintly (not shown). The steroid-producing Leydig cells in human testes showed intense immunofluorescene with all APS I sera, whereas no such staining was observed with the 15 sera taken from patients with idiopathic Addison's disease (Fig. 1, $D$ and $E$ ).

Western blot analysis. The mitochondrial fraction from homogenized bovine adrenal glands was found to be a rich source of the APS I autoantigen. All five sera from APS I patients identified a protein in the Western blot with an apparent molecular mass of $53 \mathrm{kD}$. The results are illustrated in Fig. 2, which shows a Western blot with a typical APS I serum, a serum taken from an adult patient with idiopathic Addison's disease, and different antisera raised against cytochrome P450 enzymes in adrenal steroid biosynthesis. It can be seen that the mobilities of the various enzymes were readily resolved in the system used. The serum from the patient with Addison's disease identified a protein that comigrated with the known autoantigen (Fig. 2, lanes $D$ and $E$ ), the 21-hydroxylase (7). In the same system, the serum from the APS I patient detected a 53-kD protein that comigrated with the cytochrome $\mathrm{P} 450$ cholesterol SCC (Fig. 2, lanes $A$ and $B$ ). None of the sera from the 15 patients with idiopathic Addison's disease identified this 53-kD band (not shown) and no bands in this molecular mass region were observed when sera from 15 healthy blood donors were tested. The $17 \alpha$-hydroxylase and the $11 \mathrm{~b}$-hydroxylase enzymes were identified with specific rabbit antisera and these enzymes did not comigrate either with the protein recognized by the APS I sera or with that detected by the sera of patients with idiopathic Addison's disease. All the APS I sera also identified bacterially expressed SCC (12) in Western blots (Fig. 3). The serum of patient 5 reacted weakly, as in the case of the previous Western blot experiment using the adrenal mitochondrial fraction. The bacterially expressed SCC was not identified by the sera of healthy blood donors or by those of patients with idiopathic Addison's disease. When Western blots of bacterially expressed $17 \alpha$-hydroxylase were performed, four of the patient sera were negative and one patient serum (No. 2) showed a minor reactivity to $17 \alpha$-hydroxylase. This appeared when the development time for the nitrocellulose strips was prolonged to $2 \mathrm{~h}$ (Fig. 4, lane $D$ ), which contrasts with the strong reactivity of the APS I sera directed towards bacterially expressed SCC, which was detectable after $10 \mathrm{~min}$ (Fig. 4, lanes $A$ and $B$ ).

Immunoprecipitation. In immunoprecipitations of lysates of $\left[{ }^{35} \mathrm{~S}\right.$ ] methionine labeled NCI-H295 cells, the sera from five APS I patients precipitated a protein that comigrated with the protein identified by a specific rabbit anti-SCC serum (exem- plified in Fig. 5). After preclearance with specific SCC antibodies, the 53-kD reactivity disappeared completely on subsequent immunoprecipitation with sera from APS I patients. When the preclearance was carried out with the sera from healthy blood donors, a 53-kD band was clearly visible after subsequent immunoprecipitation with APS I sera (exemplified in Fig. 5, lane $D$ ).

Inhibition of enzyme activity. The sera of all five APS I patients were tested in an enzyme assay using adrenal mitochondria and were found to markedly inhibit the conversion of cholesterol to pregnenolone, a reaction catalyzed by the side chain cleavage enzyme. The mean reduction in the enzyme activity was $84 \%$ (range, 78-92\%) ( Table II) as compared with that produced by the sera of six healthy blood donors. In a separate experiment, the serum from patient 1 was compared with a control serum at different dilutions and displayed a dose-dependent inhibition of the SCC activity (Fig. 6).

21-hydroxylase. No reactivity directed towards 21-hydroxylase was observed with the five APS I sera investigated by Western blot analysis or in the immunoprecipitations of the labeled adrenocortical cell line NCI-H295 (Figs. 2 and 5)(7). The five sera also failed to identify the 21-hydroxylase when immunoprecipitations of $\left[{ }^{35} \mathrm{~S}\right]$ methionine-labeled lysates of $\mathrm{CHO}$ cells, stably transformed with the human 21-hydroxylase cDNA (22), were performed (not shown), whereas the sera of all patients with idiopathic Addison's disease identified this enzyme as previously shown (7). As mentioned above (Fig. 2, lane F), the Addison sera displayed no reactivity towards SCC when tested against a large amount of bacterially expressed SCC in a sensitive Western blot analysis.

\section{Discussion}

In this study we have identified the major adrenal autoantigen of patients with APS I as the cytochrome P450 cholesterol side chain cleavage enzyme. All the five tested sera from APS I patients identified SCC as the autoantigen in Western blots of bovine adrenal mitochondrial fractions, in Western blots of bacterially expressed SCC, and in immunoprecipitations of the radio-labeled human adrenocortical cell line NCI-H295. The sera stained all cell layers in the cortex with a preference for the outermost layer (zona glomerulosa) of the adrenal cortex as well as the Leydig cells of the testes, both tissues known to be rich in SCC. Furthermore, all five sera inhibited the mitochondrial conversion of cholesterol to pregnenolone, the reaction catalyzed by the side chain cleavage enzyme. A weaker reactivity at immunoblotting was observed with the serum of patient 5 , which might have been due to the immunosuppressive therapy given to this patient. Another possible explanation is that the antibodies present in this serum may have been directed towards epitopes sensitive to conformational changes occurring during the Western blot procedure. The fact that the antibody titers as reflected in the immunofluorescence with sections of adrenal glands or testes were equal to those observed in the other four sera favors the latter interpretation. The serum of patient 5 also markedly inhibited SCC activity.

The cholesterol side chain cleavage enzyme is a mitochondrial enzyme that is rate limiting in adrenal steroid biosynthesis. It has been cloned (23) and the gene is located on chromosome 15 . The calculated molecular mass of $54 \mathrm{kD}(24)$ is very close to the apparent migration of $53 \mathrm{kD}$ observed in our experimental system. Like many of the enzymes involved in adrenal steroid biosynthesis, SCC is a cytochrome $\mathrm{P} 450$ protein con- 

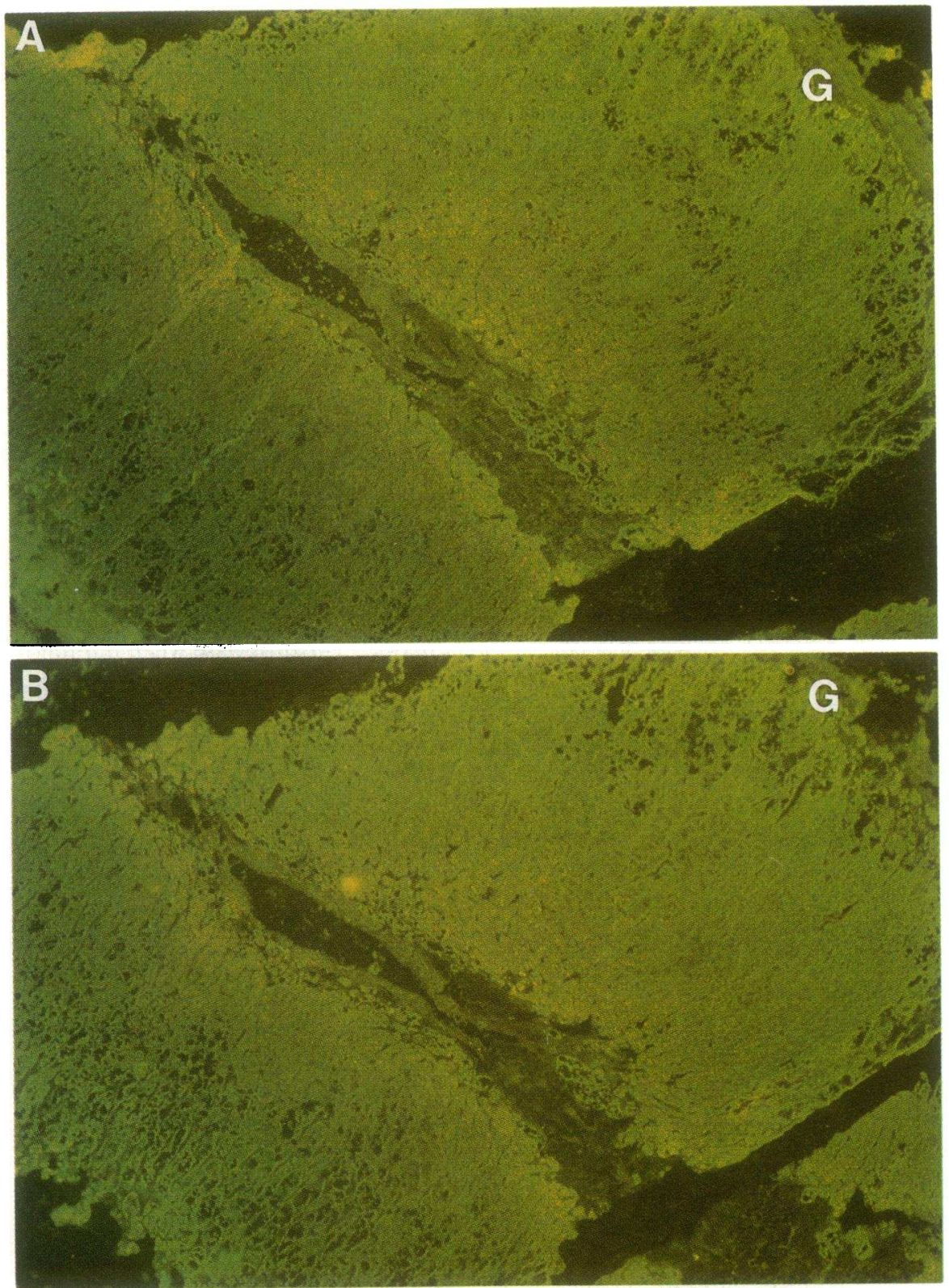

C
Figure 1. Indirect immunofluorescence of parallel sections of a human adrenal gland $(A-C, \times 8)$ and human testis $(D-F, \times 20)$, using sera, diluted to 1:20, from an APS I patient (No. 1) ( $A$ and $D$ ), a patient with Addison's disease ( $B$ and $E$ ), and a healthy blood donor $(C$ and $F)$. The location of the adrenal zona glomerulosa $(G)$ in $A-C$ and the position of the interstitial steroidproducing Leydig cells $(L)$ in $D-F$ have been indicated. 

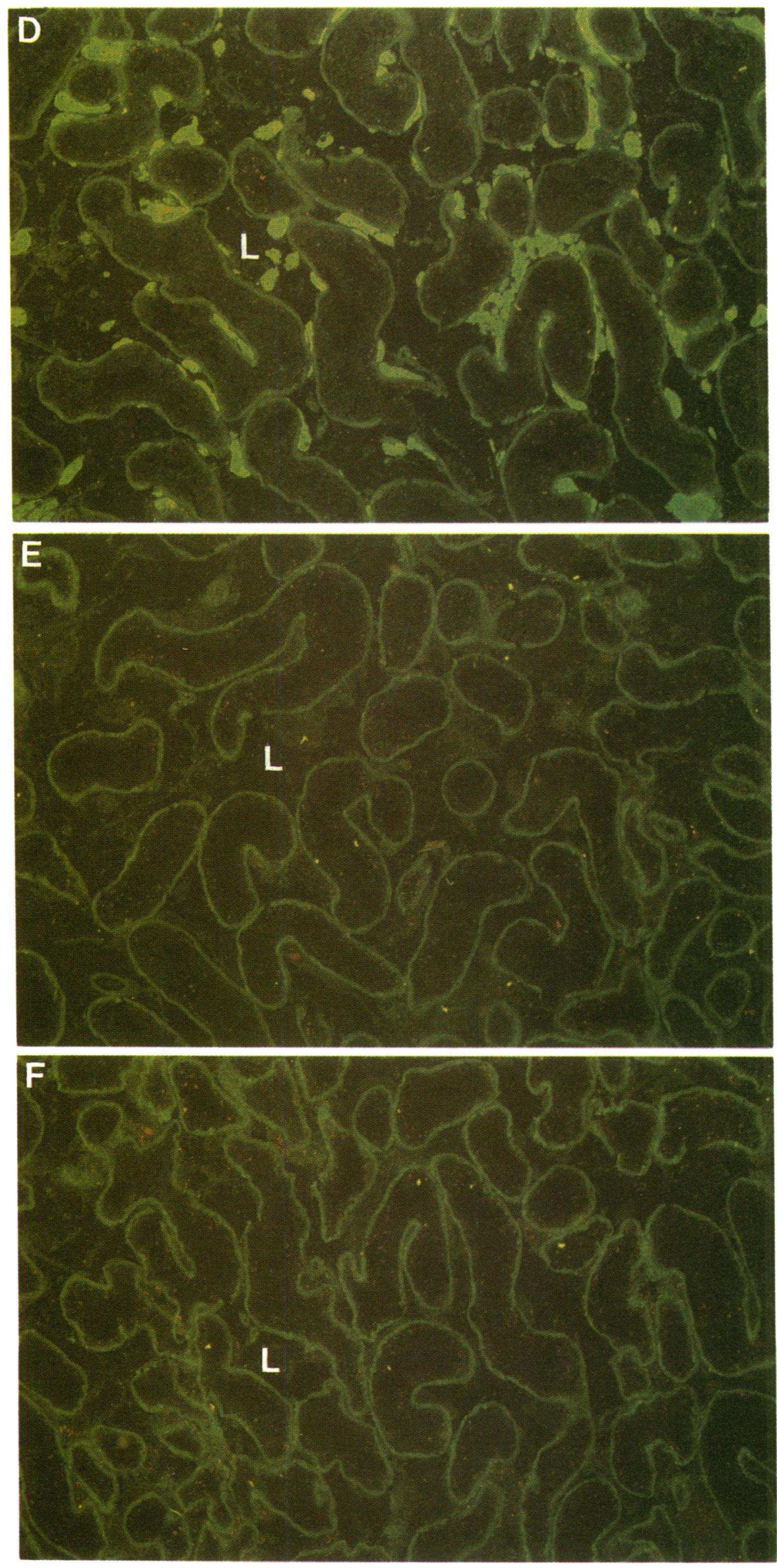

Figure 1. (Continued) 


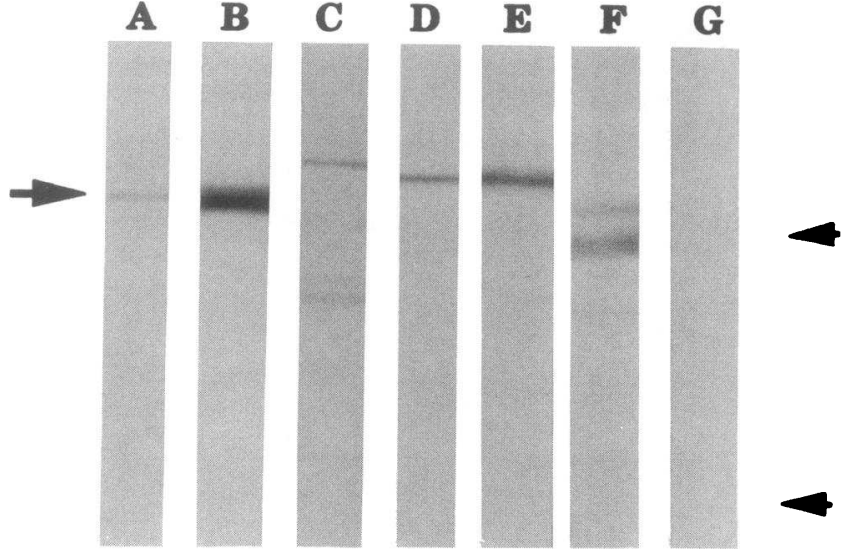

Figure 2. Western blot of a bovine mitochondrial fraction, using $50 \mu \mathrm{g}$ of total protein, with serum from an APS I patient (No. 1) (lane $A$ ), rabbit antisera against P450SCC (lane $B$ ), and $17 \alpha$-hydroxylase (lane $C)$, serum from a patient with idiopathic Addisons' disease (lane $D$ ), rabbit antisera against 21 -hydroxylase (lane $E$ ), and $11 \beta$-hydroxylase (lane $F$ ), and a serum from a healthy blood donor (lane $G$ ). Lefthand arrow indicates the presence of the APS I adrenal autoantigen. Right-hand arrows indicate two of the prestained standards, 49.5 and $32.5 \mathrm{kD}$, respectively, included in all lanes.

taining a prosthetic heme group. The enzymatic activity also requires adrenodoxin, adrenodoxin reductase, and NADPH (25). A genetic defect of this enzyme causes a rare form of congenital adrenal hyperplasia, lipid storage disease, characterized by an excessive intraadrenal accumulation of cholesterol.

Krohn et al. (26) recently reported $17 \alpha$-hydroxylase to be the adrenal autoantigen in APS I as assessed from the screening of a human fetal adrenal cDNA $\lambda$ gt 11 library with serum pooled from one APS I patient and followed by sequencing of positive clones. The authors also found reactivity towards bacterially expressed enzyme in Western blot analysis (26). In contrast, we did not detect any reactivity directed towards the $17 \alpha$-hydroxylase with APS I sera in Western blots, using adrenal mitochondrial and microsomal (not shown) fractions (Fig.

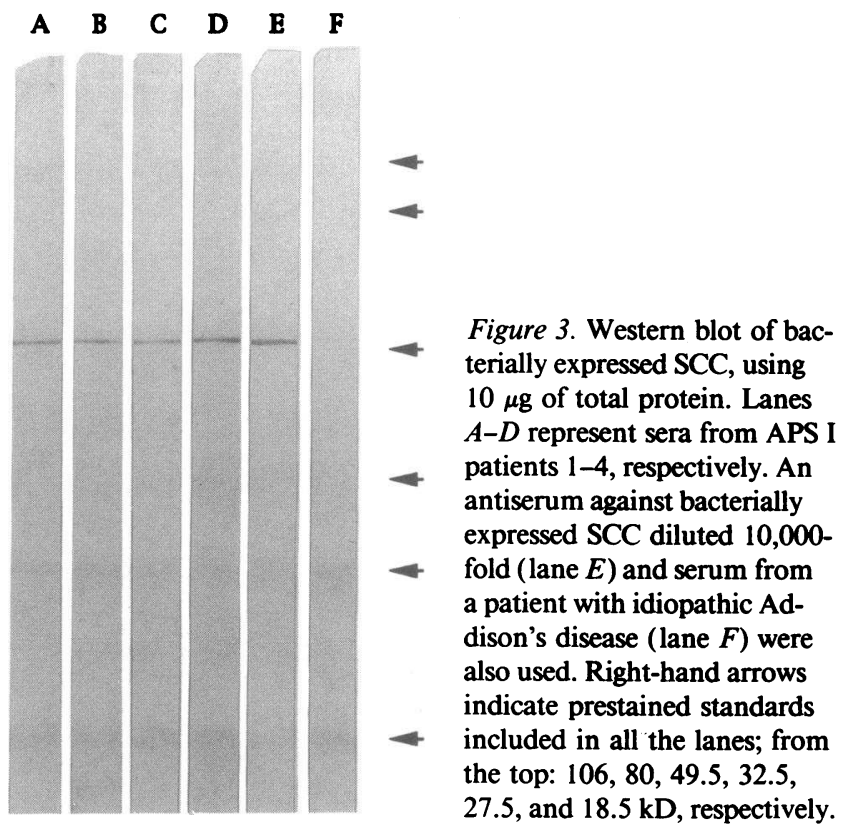

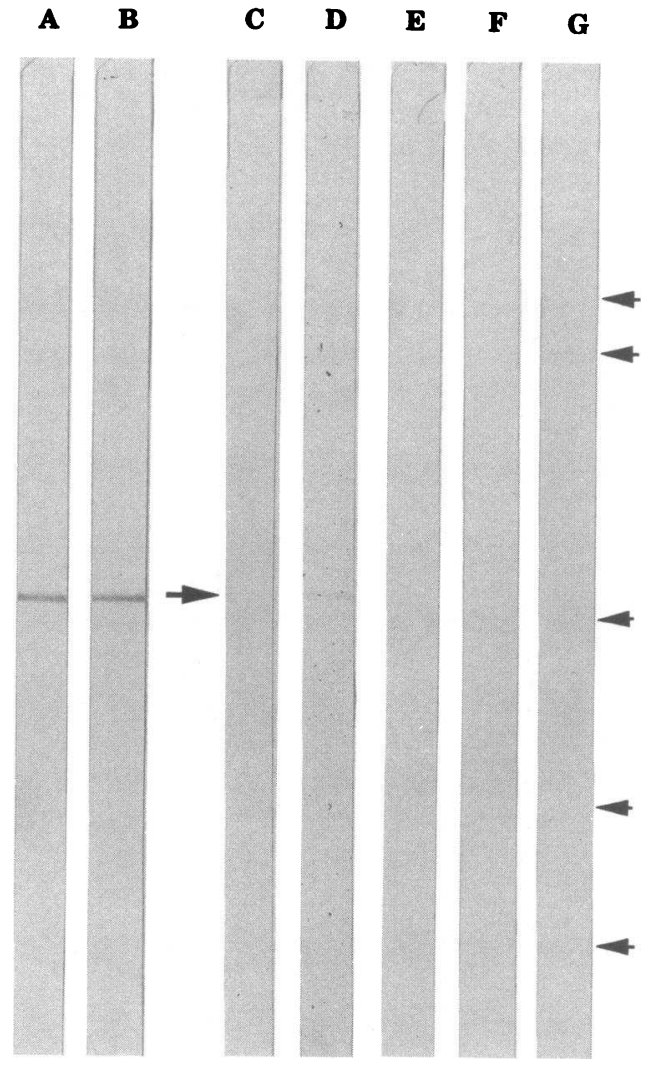

Figure 4. Western blot of bacterially expressed SSC (lanes $A$ and $B$ ) and bacterially expressed $17 \alpha$-hydroxylase (lanes $C-G$ ) with $10 \mu \mathrm{g}$ of total protein in each lane. (Lanes $A$ and $B$ ) Two sera from patients with APS I (nos. 1 and 2); (lanes $C-F$ ) sera from patients $1-4$, respectively; (lane $G$ ) a serum from a healthy blood donor. The lefthand arrow indicates the presence of the bacterially expressed $17 \alpha$-hydroxylase as determined with a specific rabbit antiserum. Right-hand arrows indicate prestained standards included in all the lanes: $106,80,49.5,32.5$, and $27.5 \mathrm{kD}$, respectively.

2). When $17 \alpha$-hydroxylase produced by bacterial expression was used, one APS I serum showed slight reactivity, whereas the other four sera were negative (Fig. 4). The patient serum that reacted weakly in this test with the $17 \alpha$-hydroxylase displayed much stronger reactivity towards the bacterially produced SCC and did not react with $17 \alpha$-hydroxylase but only with SCC in lysates from a $\left[{ }^{35} \mathrm{~S}\right]$ methionine-labeled adrenocortical cell line. With indirect immunofluorescence, the APS I sera in the present study identified the zona glomerulosa, a cell layer that does not display any $17 \alpha$-hydroxylase activity (27, 28 ), or immunoreactivity (29). Furthermore, the APS I sera also stained the rat adrenal cortex, which is known to lack $17 \alpha$-hydroxylase (28). Thus, our data strongly indicate that SCC is the major adrenal autoantigen identified by sera of patients with APS I. It is possible that when antigen produced by prokaryotic expression is used, a reactivity against $17 \alpha$-hydroxylase may occur. If so, this could represent cross-reactivity, although the overall amino acid sequence homology between SCC and $17 \alpha$-hydroxylase is only $16 \%$. However, at the heme binding site, 7 of 12 amino acids are identical.

In autoimmune adrenalitis the adrenal autoantigen seems to be well conserved between species (30), i.e., the epitope recognized by patient sera are presumably of great importance, a finding consistent with our results demonstrating an inhibi- 


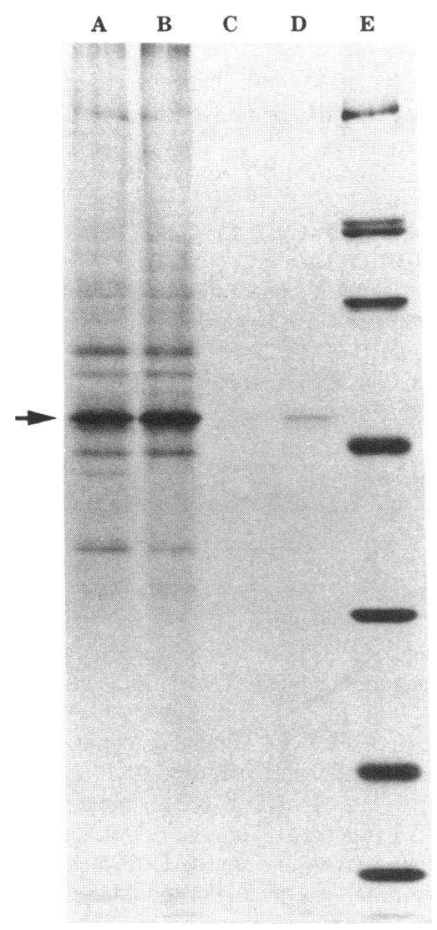

Figure 5. Immunoprecipitations of lysates from the $\left[{ }^{35} \mathrm{~S}\right]-$ methionine-labeled human adrenocortical cell line NCIH295. (Lanes $A$ and $B$ ) Preclearance with serum from a healthy blood donor followed by immunoprecipitation with APS I serum from patient No. 1 (lane $A$ ) and a rabbit antiserum against SCC (lane $B$ ), respectively. (Lanes $C$ and $D$ ) Preclearance with a serum from a normal blood donor followed by preclearance with a specific rabbit antiserum against the SSC and then immunoprecipitation with serum from APS I patient No. 1 (lane $C)$, or preclearance with serum from a healthy blood donor and then immunoprecipitation with APS I serum from patient No. 1 (lane $D$ ). When preclearance was done twice, as in lanes $C$ and $D$, a further reduction in background was ob-

tained. (Lane $E$ ) Molecular mass standards from above: 200, 97.4, $69,46,30,21.5$, and $14.3 \mathrm{kD}$.

tion of the cholesterol side chain cleavage activity in the presence of sera from patients with APS I. Both linear and presumably nonlinear epitopes were recognized by APS I sera, i.e., the sera identified SCC in Western blots of adrenal fractions and of bacterially expressed proteins containing linear epitopes. The sera precipitated SCC and inhibited the enzymatic reactivity indicating reactivity towards native epitopes. These findings are consitent with earlier reports concerning autoimmune hepatitis type II where the cytochrome P450 dbI is the target of the autoantibodies. These autoantibodies inhibit the enzymatic activity of the cytochrome $\mathrm{P} 450 \mathrm{dbI}$ and recognize linear epitopes of this enzyme in Western blots ( 31 ). In contrast, monoclonal antibodies and polyclonal sera, recognizing differences between antigens, react towards nonconserved epitopes usually not involved in specific functions of the proteins.

We have recently shown that 21 -hydroxylase is the major autoantigen in idiopathic Addison's disease of adult onset (7),

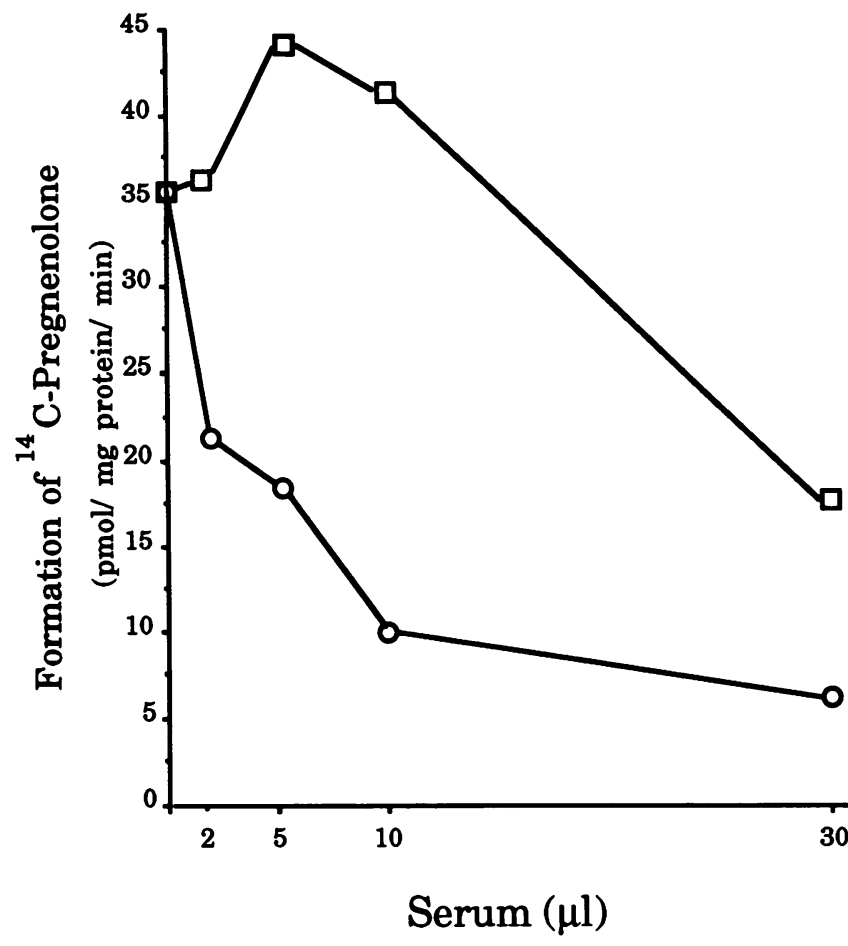

Figure 6. Conversion of $\left[4-{ }^{14} \mathrm{C}\right]$ cholesterol to pregnenolone in a bovine mitochondrial fraction incubated as described in Methods in the prescence of APS I serum (o; patient No. 1) or control serum from a healthy blood donor $(\square)$.

and this finding has since been confirmed (32). Interestingly, 21-hydroxylase is expressed only in the adrenal glands, whereas SCC is also present in the gonads. This difference is likely to reflect the broader clinical picture, including gonadal insufficiency that is often seen in APS I but not in idiopathic Addison's disease. The cytochrome P450 cholesterol side chain cleavage enzyme is not, however, present in all tissues that may be affected in APS I, and, for example, the liver and the parathyroid glands do not stain when a rabbit antiserum against $S C C$ is used (not shown). We have previously reported the occurence of a decreased 25-hydroxylation of vitamin $D$ in a patient with chronic active hepatitis, as part of APS I (11). It is tempting to speculate that a vitamin D 25-hydroxylase could be a candidate hepatic autoantigen, since, like SCC and 21-hydroxylase activities, vitamin D hydroxylation is $\mathrm{P} 450$ dependent. The mito-

Table II. Summary of Performed Investigations

\begin{tabular}{|c|c|c|c|c|c|c|c|c|c|}
\hline \multirow[b]{2}{*}{ Patient } & \multicolumn{2}{|c|}{ Immunofluorescence } & \multicolumn{4}{|c|}{ Western blot } & \multicolumn{2}{|c|}{ Immunoprecipitation } & \multirow{2}{*}{ 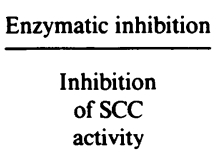 } \\
\hline & $\begin{array}{l}\text { Adrenal } \\
\text { cortex }\end{array}$ & $\begin{array}{l}\text { Leydig } \\
\text { cells }\end{array}$ & $\begin{array}{l}\mathrm{SCC} \text { in an } \\
\text { adrenal } \\
\text { fraction }\end{array}$ & $\begin{array}{l}\text { Bacterially } \\
\text { expressed } \\
\text { SCC }\end{array}$ & $\begin{array}{c}\text { Bacterially } \\
\text { expressed } \\
17 \alpha-\mathrm{OH}\end{array}$ & $\begin{array}{l}\text { Eukaryotic } \\
\text { expression } \\
\text { of } 21-\mathrm{OH}\end{array}$ & $\begin{array}{c}\text { Single } \\
\text { precipitations } \\
\text { of SCC }\end{array}$ & $\begin{array}{l}\text { Sequential } \\
\text { precipitations } \\
\text { of SCC }\end{array}$ & \\
\hline & & & & & & & & & $\%$ \\
\hline 1 & + & + & + & + & - & - & + & + & 82 \\
\hline 2 & + & + & + & + & $(+)$ & - & + & NT & 92 \\
\hline 3 & + & + & + & + & - & - & + & + & 82 \\
\hline 4 & + & + & + & + & - & - & + & NT & 85 \\
\hline 5 & + & + & + & + & - & - & + & NT & 78 \\
\hline
\end{tabular}

$+/-$ denotes presence or absence of the specified reactivity. NT, not tested. 
chondrial vitamin D 25-hydroxylase possesses significant amino acid sequence homology with SCC, with identity of 16 of 18 amino acids between positions 455 and 472 , i.e., near the heme-binding site of SCC. In contrast, the overall homology between SCC and 21-hydroxylase is only $19 \%$ and there are no stretches of more than three identical amino acids.

Today, the distinction between autoimmune adrenalitis in APS I and that in idiopathic Addison's disease is based on the age of onset and extraadrenal manifestations (2). In children who develop adrenalitis preceded by mucocutaneous candidiasis and hypoparathyroidism, the diagnosis is not difficult. However, when adrenalitis is the only presenting symptom in a young patient, it may be difficult to decide whether it is an isolated adrenalitis or an adrenalitis associated with the more serious APS I. Patients with APS I may develop additional symptoms as they grow older (4), and have to be monitored because of the risk of developing hypocalcemia, malabsorption, chronic active hepatitis, and gonadal insufficiency. We are currently developing convenient autoantibody assays based on recombinant expression of the two autoantigens.

The adrenal autoantigens associated with APS I and idiopathic Addison's disease are intracellular enzymes, as in the case of several other autoimmune diseases, such as thyroid peroxidase in autoimmune thyroiditis (33), $\mathrm{H}^{+} \mathrm{K}^{+}$-ATPase in autoimmune gastritis (34), and glutamate decarboxylase in diabetes mellitus (35). The predilection for enzymes as autoantigens in autoimmune diseases $(36,37)$ is intriguing. The inhibition of SCC activity shown (Fig. 6 and Table II) implies that some autoantibody epitopes are present near the catalytic and/or substrate-binding sites of the enzyme. This suggests that the humoral immune response is directed towards conserved parts of the enzyme and may favor the idea that certain amino acid sequences, evolutionary preserved for the maintenance of enzymatic activity, are of importance in provoking an autoimmune response ( 7 ). It could be argued that the production of autoantibodies to the enzymes merely reflects an unspecific discharge of intracellular proteins after a primary cellular attack on the target organ. However, the results obtained in the present study illustrate a selectivity in the pathogenetic events, since no reactivity towards 21 -hydroxylase could be detected in APS I sera, and, likewise, no reactivity towards SCC was observed in any of the sera from the patients with Addison's disease, even though a highly sensitive technique with recombinantly produced proteins was used. Thus, autoantibody production during the course of autoimmune adrenalitis may not merely represent secondary events but rather result from very specific immune processes.

\section{Acknowledgments}

The excellent technical assistance of Majstin Wik-Lundberg and AnnaCarin Sundell is gratefully acknowledged. We are indebted to Dr. B. C. Chung (Institute of Molecular Biology, Academia, Sinica, Nankang, Taipei, Taiwan) for the gift of the pET-SCC vector, Drs. P. C. White and M. New (Division of Pediatric Endocrinology, Cornell University Medical College, New York, NY) for the kind gift of a rabbit antiserum raised against the 21-hydroxylase and the p21-T7-f1 vector, Dr. M. R. Waterman (Department of Biochemistry, University of Texas, Dallas, TX) for the gift of the plasmid pCWmod 17, and Dr. L. Rask (Swedish University of Agricultural Sciences, Uppsala, Sweden) for providing the Staphylococcus aureus.

This study was supported by grants from the Swedish Medical Research Council and the Swedish Cancer Society.

\section{References}

1. Spinner, M. W., R. M. Blizzard, and B. Childs. 1968. Clinical and genetic heterogeneity in idiopathic Addison's disease and hypoparathyroidism. J. Clin. Endocr. 28:795-804

2. Neufeld, M., N. K. Maclaren, and R. Blizzard. 1980. Autoimmune polyglandular syndromes. Pediatr. Ann. 9:154-162.

3. Trence, D. L., J. E. Morley, and B. S. Handwerger. 1984. Polyglandular autoimmune syndromes. Am. J. Med. 77:107-116.

4. Ahonen, P., S. Myllärniemi, I. Sipilä, and J. Perheentupa. 1990. Clinical variation of autoimmune polyendocrinopathy-candidiasis-ectodermal dystrophy (APECED) in a series of 68 patients. $N$. Engl. J. Med. 322:1829-1836.

5. Blizzard, R. M., and J. H. Gibbs. 1968. Candidiasis: studies pertaining to its association with endocrinopathies and pernicious anemia. Pediatrics. 42:231237.

6. Arulanantham, K., J. M. Dwyer, and M. Genel. 1979. Evidence for defective immunoregulation in the syndrome of familial candidiasis endocrinopathy. N. Engl. J. Med. 300:164-168.

7. Winqvist, O., F. A. Karlsson, and O. Kämpe. 1992. 21-hydroxylase, a major autoantigen in idiopathic Addison's disease. Lancet. 339:1559-1562.

8. Ahonen, P., S. Koskimies, M. L. Lokki, A. Tiilikainen, and J. Perheentupa. 1988. The expression of autoimmune polyglandular disease type I appears associated with several HLA-A antigens but not with HLA-DR. J. Clin. Endocrinol. \& Metab. 66:1152-1157.

9. Riley, W. J., N. K. Maclaren, and M. Neufeld. 1980. Adrenal autoantibodies and Addison disease in insulin-dependent diabetes mellitus. J. Pediatr. 97:191-195.

10. Maclaren, N. K., and W. J. Riley. 1986. Inherited susceptibility to autoimmune Addison's disease is linked to human leukocyte antigens DR3 and/or DR4, except when associated with autoimmune polyglandular syndrome. $J$. Clin. Endocrinol. \& Metab. 62:455-459.

11. Gustafsson, J., I. Holmberg, L. I. Hardell, and T. Foucard. 1984. Hypoparathyroidism and liver disease - evidence for a vitamin $\mathrm{D}$ hydroxylation defect. Acta Endocrinol. 905:211-214.

12. Hu, M. C., I. C. Guo, J. H. Lin, and B. C. Chung. 1991. Regulated expression of cytochrome P450SCC (cholesterol-side-chain cleavage enzyme) in cultured cell lines detected by antibody against bacterially expressed human protein. Biochem. J. 274:813-817.

13. Barnes, H. J., M. P. Arlotto, and M. R. Waterman. 1991. Expression and enzymatic activity of recombinant cytochrome P450 17 $\alpha$-hydroxylase in Escherichia coli. Proc. Natl. Acad. Sci. USA. 88:5597-5601.

14. Gazdar, A. F., H. K. Oie, C. H. Shackleton, T. R. Chen, C. A. Stein, and R. V. L. Rocca. 1990. Establishment and characterization of a human adrenocortical carcinoma cell line that expresses multiple pathways of steroid biosynthesis. Cancer Res. 50:5488-5496.

15. Kämpe, O., A. Andersson, E. Björk, A. Hallberg, and F. A. Karlsson. 1989. High-glucose stimulation of $64,000 \mathrm{M}_{\mathrm{r}}$ islet cell autoantigen expression Diabetes. 38:1326-1328.

16. Björkhem, I., and K. E. Karlmar. 1975. A novel technique for assay of side-chain cleavage of exogenous and endogenous cholesterol in adrenal mitochondrial and submitochondrial preparations. Anal. Biochem. 68:404-414.

17. Björkhem, I., and J. Gustafsson. 1974. Mitochondrial w-hydroxylation of cholesterol side-chain. J. Biol. Chem. 249:2528-2535.

18. Takikawa, O., T. Gomi, K. Suhara, E. Itagaki, S. Takemori, and M. Katagiri. 1978. Properties of an adrenal cytocrome P450 (P450SCC) for the side-chain cleavage of cholesterol. Arch. Biochem. Biophys. 190:300-306.

19. Blizzard, R. M., M. A. Kyle, R. W. Chandler, and W. Hung. 1962. Adrenal antibodies in Addison's disease. Lancet. i:901-903.

20. Irvine, W. J., A. G. Stewart, and L. Scarth. 1967. A clinical and immunological study of adrenocortical insufficiency (Addison's disease). Clin. Exp. Immunol. 2:31-70.

21. Elder, M., N. K. Maclaren, and W. Riley. 1981. Gonadal autoantibodies in patients with hypogonadism and/or Addison's disease. J. Clin. Endocrinol. \& Metab. 52:1137-1142.

22. Tusie-Luna, M. T., P. Traktman, and P. C. White. 1990. Determination of functional effects of mutations in the steroid 21-hydroxylase gene (CYP21) using recombinant vaccinia virus. J. Biol. Chem. 265:20916-20922.

23. Chung, B. C., K. J. Matteson, R. Voutilainen, T. K. Mohandas, and W. L. Miller. 1986. Human cholesterol side chain cleavage enzyme, P 450 scc: cDNA cloning, assignment of the gene to chromosome 15 and expression in placenta. Proc. Natl. Acad. Sci. USA. 83:8962-8966.

24. Morohashi, K., Y. Fujii-Kuriyma, Y. Okada, K. Sogawa, T. Hirose, S. Inayama, and T. Omura. 1984. Molecular cloning and nucleotide sequence of cDNA for mRNA of mitochondrial cytochrome P450(SCC) of bovine adrenal cortex. Proc. Natl. Acad. Sci. USA. 81:4647-4651.

25. Miller, W. L. 1988. Molecular biology of steroid hormone synthesis. Endocr. Rev. 9:295-318.

26. Krohn, K., R. Uibo, E. Aavik, P. Peterson, and K. Savilahti. 1992. Identification by molecular cloning of an autoantigen associated with Addison's disease as steroid $17 \alpha$-hydroxylase. Lancet. 339:770-773. 
27. Harkins, J. B., E. B. Nelson, B. S. S. Masters, and G. T. Bryan. 1974. Preparation and properties of microsomal membranes from isozonal cells of beef adrenal cortex. Endocrinology. 94:897-902.

28. Hornsby, P. J. 1985. The regulation of adrenocortical function by control of growth and structure. In Adrenal Cortex. D. C. Anderson and J. S. D. Winter, editors. Butterworth-Heinemann Ltd., London. 1-31.

29. Sasano, H., J. I. Mason, and N. Sasano. 1989. Immunohistochemical analysis of cytochrome P450 17 $\alpha$-hydroxylase in pig adrenal cortex, testis and ovary. Mol. Cell. Endocrinol. 62:197-202.

30. Blizzard, R. M., and M. Kyle. 1963. Studies of the adrenal antigens and antibodies in Addison's disease. J. Clin. Invest. 42:1653-1660.

31. Manns, M. 1989. Autoantibodies and antigens in liver disease-updated. $J$. Hepatol. 9:272-280.

32. Bauman-Antczak, A., N. Wedlock, J. Bednarek, Y. Kiso, H. Krishnan, S. Fowler, B. Rees Smith, and J. Furmaniak. 1992. Autoimmune Addison's disease and 21-hydroxylase (letter). Lancet. 340:429-430.
33. Czarnocka, B., J. Ruf, M. Ferrand, P. Carayon, and S. Lissitsky. 1985. Purification of the human thyroid peroxidase and its identification as the microsomal antigen involved in autoimmune thyroid disease. FEBS (Fed. Eur. Biochem. Soc.) Lett. 190:147-151.

34. Karlsson, F. A., P. Burman, L. Lööf, and S. Mårdh. 1988. The major parietal cell antigen in autoimmune gastritis with pernicious anemia is the acid producing H,K ATPase of the stomach. J. Clin. Invest. 81:475-479.

35. Baekkeskov, S., H. J. Aanstoot, S. Christgau, A. Reetz, M. Solimena, M. Cascalho, F. Folli, H. Richter-Olesen, and P. D. Camilli. 1990. Identification of the $64 \mathrm{~K}$ autoantigen in IDDM as the GABA synthesizing enzyme glutamic acid decarboxylase. Nature (Lond.). 347:151-156.

36. Banga, J. P., and A. M. McGregor. 1991. Enzymes as targets for autoantibodies in human autoimmune disease: relevance to pathogenesis. Autoimmunity. 9:177-182.

37. Tan, E. M. 1991. Autoantibodies in pathology and cell biology. Cell. 67:841-2. 